\title{
Contact dermatitis caused by methacrylates in nail products
}

\author{
Samuel DeKoven BSc, D. Linn Holness MD MHSc
}

Cite as: CMAJ 2017 September 18;189:E1193. doi: 10.1503/cmaj.170264

A 33-year-old woman presented to the patch test clinic with eczema around the nail folds of both hands, which appeared 12 hours after having shellac nail polish applied at a nail salon (Figure 1). The patient reported that she had had similar reactions with artificial gel nails two years earlier, which subsided when she stopped using artificial nails.

On examination, there was mild redness and scale around her nails. Patch testing with the North American Contact Dermatitis Group Standard Series and an acrylate and methacrylate series revealed reactions to multiple acrylates and methacrylates. We made a diagnosis of allergic contact dermatitis caused by her nail products.

Methacrylates are compounds found in all artificial sculpted nails and shellac nail polish. They are also commonly found in dental materials and orthopedic bone cement. ${ }^{1}$ Increasingly, methacrylates are becoming common contact allergens among consumers and nail technicians. ${ }^{1}$ About $2.6 \%$ of patients with contact dermatitis react to hydroxyethyl methacrylate (the most commonly sensitizing methacrylate) on patch testing. ${ }^{2}$ The nail salon industry is estimated to generate over $\$ 8$ billion annually in the United States; in a 2014 survey, over $93 \%$ of salons offered gel nail products containing methacrylates. ${ }^{3}$

The differential diagnosis for dermatitis affecting the nail folds includes psoriasis, tinea manuum, irritant contact dermatitis and allergic contact dermatitis. Diagnosis of allergic contact dermatitis is confirmed by patch testing; physicians should refer patients who use or work with nail products for testing if they present with dermatitis of the nail fold or fingertip.

If contact allergy has been identified, patients must avoid all methacrylates because of substantial cross-reactivity and cosensitization between various methacrylates. ${ }^{1}$

In the workplace, nail technicians can reduce risk by avoiding use of methacrylates. If use cannot be eliminated, technicians may use more protective glove materials such as nitrile, double glove when working with products containing methacrylate and change gloves frequently. ${ }^{1}$

\section{References}

1. Muttardi K, White IR, Banerjee P. The burden of allergic contact dermatitis caused by acrylates. Contact Dermatitis 2016;75:180-4.

2. DeKoven JG, Warshaw EM, Belsito DV, et al. North American Contact Dermatitis Group Patch Test Results 2013-2014. Dermatitis 2017;28:33-46.

3. Nails Magazine big book 2014-2015. Nails Magazine 2015. Available: http://files. nailsmag.com/Market-Research/NABB2014-2015-Stats-2-1.pdf (accessed 2017 Aug. 4).

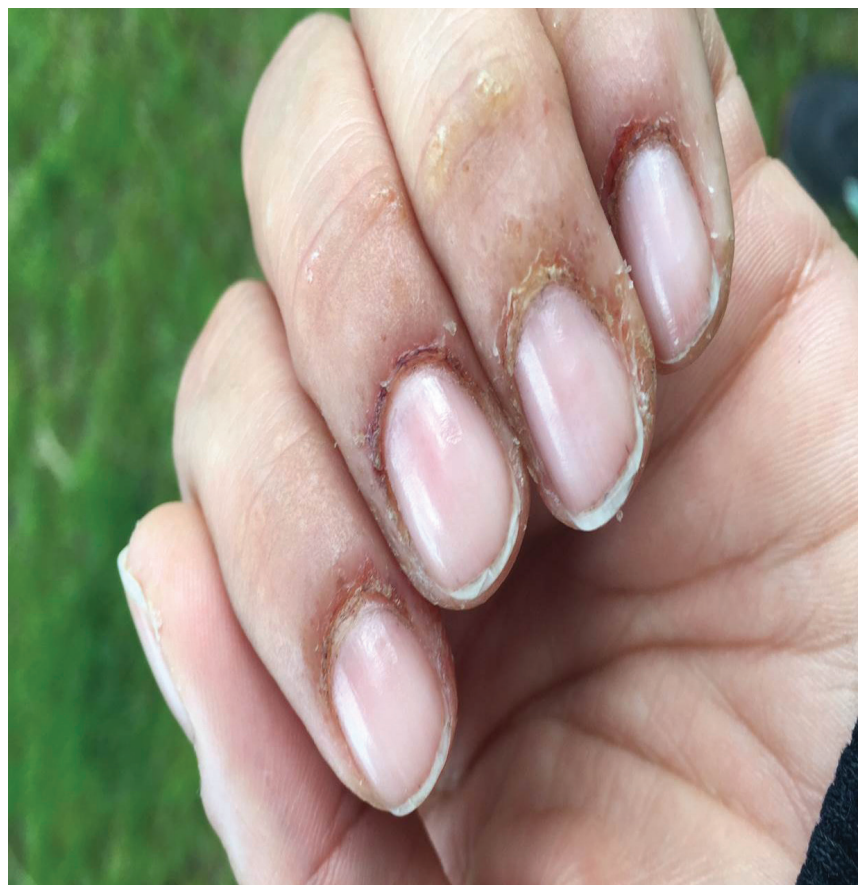

Figure 1: Dermatitic eruption of the nail folds caused by methacrylate contact dermatitis from shellac nail polish in a 33-year-old woman with nail polish removed.

Competing interests: Samuel DeKoven received a summer research studentship grant from the Centre for Research Expertise in Occupational Disease, which is funded by the Ontario Ministry of Labour. No other competing interests were declared.

This article has been peer reviewed.

The authors have obtained patient consent.

Affiliations: Doctor of Medicine Program (DeKoven), Schulich School of Medicine and Dentistry, London, Ont.; Division of Occupational Medicine (DeKoven, Holness), Department of Medicine, St. Michael's Hospital; Dalla Lana School of Public Health and Department of Medicine (Holness), University of Toronto; Centre for Urban Health Solutions (Holness), Li Ka Shing Knowledge Institute, St. Michael's Hospital, Toronto, Ont.

Acknowledgement: The authors thank Dr. Joel DeKoven for his help with crafting and revision of the manuscript.

Correspondence to: Samuel DeKoven, sdekoven2018@meds.uwo.ca 